\title{
Demographic and Social Correlates of Suicide in the Czech Republic*
}

\author{
DAGMAR DZÚROVÁ, LADO RUZICKA, EVA DRAGOMIRECKÁ** \\ Charles University, Prague, Academy of Social Sciences \\ in Australia, Braidwood, Prague Psychiatric Centre
}

\begin{abstract}
In this article the authors review the trends and differentials in mortality from self-inflicted injury and poisoning in the Czech Republic between the early 1970s and the present in terms of their socio-economic and demographic associations. They describe the sources of data on suicide and explore the possible extent of under-reporting of deaths from suicide, and they examine the differences in suicide incidence by age and sex. With the decline in mortality from suicide, the male/female ratio of suicide rates increased from about 2.6 in the early 1970 s to around 4.0 in recent years. Suicide rates increase steadily with age, and this pattern did not noticeably change during the period reviewed. The agespecific suicide rates of older men and women declined more than the rates for younger people. As in other societies, married men and women have the lowest suicide rates; in contrast, divorce puts both men and women at the greatest risk of suicide. The authors attempt to investigate the social correlates of suicide by analysing the variation in suicide rates among districts in the Czech Republic and selected socio-economic and demographic characteristics of the district populations. Stepwise regression analysis is used to identify three independent variables that explain $50 \%$ of the variation in suicide rates among districts: the abortion ratio, the percentage of locally born population, and the percentage of adults with limited education.
\end{abstract}

Keywords: suicide, difference, gender, age, marital status

Sociologický časopis/Czech Sociological Review, 2006, Vol. 42, No. 3: 557-571

\footnotetext{
* This manuscript was supported in part by the Ministry of Education, Youth and Sports of the Czech Republic, grant no. MSM 0021620831.

** Direct all correspondence to: Dagmar Dzúrová, Department of Social Geography and Regional Development, Faculty of Sciences, Charles University, Albertov 6, 12843 Prague 2, Czech Republic, e-mail: dzurova@natur.cuni.cz; Lado Ruzicka, Academy of the Social Sciences in Australia, Majors Creek nr.Braidwood, NSW 2622, Australia, e-mail: ladoruz@braidwood.net.au; Eva Dragomirecká, Prague Psychiatric Centre, Department of Social Psychiatry, Ústavní 91, 18103 Prague 8 Bohnice, Czech Republic, e-mail: dragomirecka@pcp.lf3.cuni.cz.
}

(C) Sociologický ústav AV ČR, Praha 2006 


\section{Introduction}

Intentionally self-inflicted harm, irrespective of whether it results in death (suicide) or leaves no substantive damage to the person's health (attempted suicide or parasuicide), has been the subject of study by social and medical scientists since about the middle of the 19th century. Prior to that it had been the domain of theologians and philosophers, arguing the case of an individual's right to terminate their life. At the forefront of medical research has been the issue of the victim's mental health. Sociologists, and later demographers and epidemiologists, have searched for patterns in self-destructive acts and in the characteristics of their agents in an attempt to develop a framework for preventive actions and policies. This article is intended to contribute to the understanding of suicidal behaviour and its patterns and trends in the Czech Republic.

\section{Data sources}

As in Western countries, there are three types of statistics on suicide in the Czech Republic: 1) the cause-of-death statistics published by the Czech Statistical Office (CSO); 2) the statistics on suicides and para-suicides collated and published by the Institute of Health Information and Statistics of the Czech Republic (IHIS CR); and 3) the statistics on deaths investigated by the police. Owing largely to the differences in the procedures used to collect these data, the latter two sources record fewer deaths by suicide than the CSO. For instance, in the period between 1996 and 2000 the CSO's cause-of-death statistics recorded 8106 deaths from intentional selfinflicted harm, while the IHIS CR reported only 7618 cases, and police records indicated a mere 6178 suicides. Yet even the cause-of-death statistics are undoubtedly an under-estimate of the true incidence of suicide. It is the coroner's verdict that determines whether a death is to be attributed to suicide. It is the practice of coroners to ascribe a death from self-inflicted injury or poisoning to suicide if there is proof 'beyond a reasonable doubt' that the victim intended to end his/her life. In questionable cases the death is attributed either to the category of causes where the intention remains undecided, or, alternatively, it is deemed an accident. In the Tenth Revision of the International Classification of Diseases of the World Health Organisation (ICD-10) deaths from intentional self-inflicted injuries and poisonings are coded as $\mathrm{X} 60-\mathrm{X} 84$ and those deaths where the intention remained undecided as Y10-Y34. In the Czech Republic, the ratio between self-inflicted deaths of uncertain intent to one hundred deaths unequivocally attributed to suicide has in recent years hovered between 18 and 20 [Dzúrová and Dragomirecká 2002: 9]. This ratio varies considerably by age and sex and by the method of suicide. In 1990-2000, the ratio was 20.2 and 18.5 per hundred recorded suicides of women and men, respectively. The highest ratio was in those instances where a young person under the age of 20 committed suicide. There was a higher ratio than the overall average among the very elderly. With respect to the method of suicide, in 1999-2000 the highest ratio 
Table 1. Estimate of the potential under-reporting of suicides, Czech Republic, 1999-2000

\begin{tabular}{lrr}
\hline \multicolumn{2}{l}{ Cause of death (ICD-10) } & $\begin{array}{r}\text { Number } \\
\text { of deaths }\end{array}$ \\
\hline X60-X84 & Intentional self-inflicted injury \& poisoning & 3259 \\
Y10-Y34 & Event of undetermined intent & 609 \\
R 96 & Other sudden death, cause unknown & 100 \\
R 98 & Unattended death & 98 \\
R 99 & Other ill-defined and unspecified causes of death & 563 \\
W 13 & Fall from, out of or through building & 116 \\
W65-W74 & Accidental drowning and submersion & 455 \\
\hline Total of potential suicides & (Y10-Y34)/(X60-X84) \\
\multicolumn{2}{l}{ Under-reporting of suicides: Minimum } & 1941 \\
& Maximum & Total / (X60-X84) \\
\hline
\end{tabular}

Source: Czech Statistical Office

of 'uncertain' to 'certain' suicides was for deaths by poisoning from addictive drugs (Y10-Y18) - 54 'uncertain' to 100 'certain' suicides; from drowning (Y21) - 22 : 100; and from firearm discharge (Y22-Y24) - 16 : 100 [Dzúrová and Dragomirecká 2002: 11].

The potential extent of under-reporting of suicides may be quite large. O'Carroll [1989] found that in the United States the under-reporting of national suicide rates is most commonly estimated at between 40 and $80 \%$. We attempted to estimate the possible extent of under-reporting of suicides in the Czech Republic by assuming two extreme situations: a) all the deaths classified as open verdicts were in reality suicides, and b) all accidental deaths listed in Table 1 as potential were in fact disguised suicides. In the first instance, which may be considered the lower limit of the extent of under-reporting, the number of recorded suicides has to be inflated by around 19\% to account for under-reporting. In the second case, which represents the upper limit of the extent of under-reporting (and, admittedly, a most unlikely situation) the adjustment factor amounts to about $60 \%$.

In the following analyses we use deaths recorded as resulting from intentional self-harm, i.e. suicides. However, in the analysis of regional variations in suicide rates we use combined rates of recorded suicides (X60-X64) and open verdicts (Y10-Y34) in order to eliminate the possible effect of variations in the coroners' practice of determining deaths as resulting from intentional self-inflicted harm. 


\section{Trends in suicide rates: 1970-2002}

According to Dzúrová and Dragomirecká [2002] it is possible to distinguish three phases in the incidence of suicide in the Czech Republic since the end of the Second World War. During the first phase, between 1945 and 1951, suicide rates gradually declined by almost one-third: from a high point at 30 per 100000 inhabitants in 1945 to 21.5 in 1951. The second phase was one of rising suicide rates, reaching a new peak of 40 per 100000 inhabitants in 1970. The third phase, which began around 1970, has been characterised by gradually declining suicide rates. Table 2 shows the suicide rates (per 100000 inhabitants) by sex during this third phase. In the course of these thirty years the decline in suicide rates may be partly due to the increase in the amount of attention mental health has received, particularly depres-

Table 2. Incidence of suicide in the Czech Republic by sex, 1970-2002

\begin{tabular}{|c|c|c|c|c|c|c|c|}
\hline \multirow[t]{2}{*}{ Year } & & \multicolumn{2}{|c|}{ (per 100000 inhabitants) } & Year & \multicolumn{3}{|c|}{$\begin{array}{l}\text { Suicide rate } \mathrm{M} / \mathrm{F} \text { ratio } \\
\text { (per } 100000 \text { inhabitants) }\end{array}$} \\
\hline & Males & Female & & & Males & Females & \\
\hline 1970 & 41.6 & 16.8 & 2.5 & 1985 & 30.1 & 11.3 & 2.7 \\
\hline 1971 & 40.5 & 15.4 & 2.6 & 1986 & 30.6 & 11.9 & 2.6 \\
\hline 1972 & 40.1 & 16.7 & 2.4 & 1987 & 27.6 & 10.4 & 2.7 \\
\hline 1973 & 35.9 & 14.4 & 2.5 & 1988 & 27.0 & 11.3 & 2.4 \\
\hline 1974 & 36.7 & 14.5 & 2.5 & 1989 & 27.1 & 10.2 & 2.6 \\
\hline 1975 & 34.4 & 14.1 & 2.4 & 1990 & 28.5 & 10.6 & 2.7 \\
\hline 1976 & 31.9 & 13.3 & 2.4 & 1991 & 27.8 & 9.6 & 2.9 \\
\hline 1977 & 33.2 & 12.8 & 2.6 & 1992 & 29.6 & 9.5 & 3.1 \\
\hline 1978 & 33.1 & 13.7 & 2.4 & 1993 & 28.1 & 9.5 & 3.0 \\
\hline 1979 & 30.9 & 12.1 & 2.6 & 1994 & 26.7 & 10.0 & 2.7 \\
\hline 1980 & 32.0 & 12.9 & 2.5 & 1995 & 25.6 & 8.5 & 3.0 \\
\hline 1981 & 31.7 & 12.0 & 2.6 & 1996 & 23.7 & 6.6 & 3.6 \\
\hline 1982 & 31.5 & 12.3 & 2.6 & 1997 & 26.2 & 6.7 & 3.9 \\
\hline 1983 & 31.0 & 11.2 & 2.8 & 1998 & 25.3 & 6.5 & 3.9 \\
\hline \multirow[t]{4}{*}{1984} & 29.8 & 11.5 & 2.6 & 1999 & 25.7 & 6.2 & 4.2 \\
\hline & & & & 2000 & 26.0 & 6.7 & 3.9 \\
\hline & & & & 2001 & 25.9 & 6.2 & 4.2 \\
\hline & & & & 2002 & 24.5 & 6.1 & 4.0 \\
\hline
\end{tabular}

Source: Czech Statistical Office 
sive disorders and their treatment, the improvement in access to psychological and social counselling and crisis management, and the availability of more effective medication for mental disorders.

During the last decade in this period Czech society went through a phase of dramatic political, social and economic change. The political liberalisation that followed the collapse of the communist regime in 1989 and the subsequent introduction of policies aimed at the privatisation and globalisation of the Czech economy brought about significant social changes. Yet at the same time, and especially between 1996 and 2000, suicide rates dropped to the lowest levels recorded in the country in more than a century. This suggests that, contrary to expectations, the societal and political transformation of the 1990s did not result in a negative social response and an increase in suicidal behaviour [Dzúrová and Dragomirecká 2002: 26].

Suicide nonetheless continues to represent a concern and a social challenge. Although the proportion of deaths from suicide out of the total number of deaths declined between 1960-1964 and 1996-2000, from 2.5\% to 1.5\%, among young men and women aged $20-24$, suicides represented, respectively, about $20 \%$ and $30 \%$ of all deaths that occurred between 1996 and 2000 [Dzúrová and Dragomirecká 2002: 26]. The relative importance of suicides is likely to increase in the future owing to the continuing decline in the rate of mortality from natural causes.

\section{Variation of suicide incidence by gender and age}

During the period of high suicide rates in the early 1970s, males were 2.6 times as likely as females to end their lives. The gradual decline in the suicide mortality rate in over the next thirty years, which was particularly pronounced among women, resulted in the ratio of male/female suicide rates increasing to about four times as likely in recent years (Table 2).

The age pattern of suicide mortality reflects, among other things, the stage in the life cycle at which stressful circumstances overpower an individual's natural inclination for survival and to protect their life. Stressful conditions are often encountered with increasing incidence at an older age, and thus in many societies suicide rates increase with age. This trend is also noticed in the Czech Republic, where the incidence of suicide steadily increases with age for both men and women (Table 3). This pattern has not noticeably changed over time. Yet one important change has manifested itself: in the course of the decline of suicide rates the incidence of suicide among older men and women has decreased by more than $40 \%$, while among younger men the rates fluctuated, with no discernable trend. Such a fluctuation in suicide rates was also observed among men in the 20-29 age group during the 1990s. Although the numbers are not high, the phenomenon of constant or possibly even rising suicide incidence among young people is a matter of serious social concern. A rising incidence of suicide among young men has also been observed in some Western countries and has been documented by the World Health Organisa- 
Table 3. Suicide rates by age and sex. Czech Republic, selected periods (per 100000 inhabitants)

\begin{tabular}{lrrrrrrrr}
\hline Age & \multicolumn{2}{c}{$1970-1974$} & \multicolumn{2}{c}{ 1981-1985 } & \multicolumn{2}{c}{$1991-1995$} & \multicolumn{2}{c}{$1996-2000$} \\
group & Males & Females & Males & Females & Males & Females & Males & Females \\
\hline $10-14$ & 5.5 & 0.9 & 1.8 & 0.4 & 2.7 & 0.4 & 1.7 & 0.6 \\
$15-19$ & 23.9 & 10.8 & 12.3 & 4.1 & 12.8 & 2.9 & 12.0 & 2.9 \\
$20-29$ & 36.3 & 10.6 & 25.7 & 7.1 & 21.9 & 5.5 & 20.4 & 3.4 \\
$30-39$ & 40.4 & 10.4 & 34.5 & 8.6 & 31.2 & 7.8 & 27.3 & 4.8 \\
$40-49$ & 52.1 & 16.4 & 40.0 & 11.3 & 39.5 & 10.8 & 37.3 & 8.3 \\
$50-59$ & 57.0 & 21.2 & 45.7 & 15.8 & 39.3 & 13.2 & 33.7 & 8.5 \\
$60-69$ & 62.7 & 26.4 & 50.2 & 22.2 & 40.5 & 14.5 & 33.6 & 9.8 \\
$70+$ & 109.7 & 45.6 & 102.5 & 36.5 & 76.7 & 27.2 & 62.3 & 16.6 \\
\hline $10+$ & 46.0 & 18.0 & 37.1 & 13.8 & 31.7 & 10.7 & 28.6 & 7.3 \\
All ages & 39.0 & 15.5 & 30.8 & 11.7 & 27.6 & 9.4 & 25.4 & 6.5 \\
\hline
\end{tabular}

Source: Czech Statistical Office

tion [1996]. For instance, between 1960-1964 and 1990-1994 suicide mortality among males aged 15-24 increased in France from 6.7 to 18.2 per 100000 inhabitants, in Finland from 18.9 to 45.5 per 100000 inhabitants, in Norway from 4.6 to 21.9 per 100000 inhabitants, in New Zealand from 5.8 to 34.9 per 100000 inhabitants, and in Australia from 9.7 to 23.7 per 100000 inhabitants in 1993 [Ruzicka and Choi 1999: 31].

\section{Marital status and the incidence of suicide}

Apart from gender and age another demographic characteristic that has been associated with differences in the incidence of suicide is marital status. Suicide risk is considerably higher among non-married men and women than among those who are married. Two mechanisms have been suggested as plausible explanations for these differences: selection, or, alternatively, the sense of protection bestowed by marriage and having a family. In the first instance, differences in suicide rates may arise from a health-related selection process, which operates both in the marriage unit and in the breakdown of marriage in a divorce. A person's state of health may affect his/her chances of marrying; there is likely to be a relatively large proportion of people who suffer from health problems, especially mental health disorders, like drug or alcohol addition, among those who remain single, and that puts them at a greater risk of self-inflicted harm. The health status of a spouse may also affect the chances of a marriage ending in divorce. This kind of selection process may explain the higher than average suicide rates among divorced people and people who have never been married. An alternative explanation is the claim that marriage and fam- 
Table 4. Suicide rates by marital status, gender and age groups, Czech Republic, annual averages 2000-2002 (per 100000 inhabitants)

\begin{tabular}{lrrrrr}
\hline Marital status /Age groups & $<20$ & $20-24$ & $25-44$ & $45-64$ & $65+$ \\
\hline & & \multicolumn{5}{c}{ Males } \\
Currently married & 17.6 & 19.6 & 25.0 & 34.4 & 24.4 \\
Never married & 21.0 & 29.6 & 61.2 & 90.1 & 15.0 \\
Divorced & 36.9 & 57.1 & 71.7 & 52.7 & 63.7 \\
Widowed & $1035.9^{*}$ & 64.8 & 81.3 & 105.3 & 99.0 \\
Total & 20.9 & 26.4 & 34.7 & 49.1 & 25.0 \\
\hline & & & Females & & \\
Currently married & 1.4 & 3.8 & 7.5 & 9.4 & 5.9 \\
Never married & 3.2 & 7.3 & 14.3 & 11.8 & 2.7 \\
Divorced & 13.4 & 10.3 & 14.5 & 16.1 & 13.0 \\
Widowed & & 4.4 & 9.0 & 16.3 & 14.3 \\
Total & 3.0 & 5.2 & 8.9 & 13.9 & 6.6 \\
\hline Note: Based
\end{tabular}

Note: ${ }^{*}$ Based on 1 suicide and 39 widowers

ily lead to a healthier life style, reduce exposure to stress, and provide greater access to social support networks [Gove 1973; Reher 1998].

As expected, married men and women had the lowest incidence of suicide in all age groups (Table 4). Among men the highest risk of suicide is among widowers, especially elderly widowers (the extremely high suicide rate among widowers in the 20-24 age group is distorted by the very low number at risk). Widowed women appear to cope with their bereavement better than men and between the ages of 25 and 64 have suicide rates that are only slightly higher than for women still married. The breakdown of a marriage by divorce appears to put men at a lower risk of suicide than the loss of a partner owing to the latter's premature death. Women, on the other hand, seem to be exposed to a greater risk of suicide when their marriage ends in divorce than in the case of the premature death of their husband. Only at age 65 and over is the risk about the same for both types of marriage dissolution.

Reher [1998] makes a distinction between societies with strong family ties and those with relatively weak family ties and argues that in the former there is strong social cohesion and they are usually more conservative (in social though not necessarily in political terms). Social control of behaviour tends to be more effective in strong-family societies - as evinced by the low incidence of divorce and extra-marital pregnancy. In weak-family societies loneliness is one of the most significant social problems; the individual 'must confront the world and his own life without the safety net of familial support' [ibid.: 217]. According to some indicators the Czech Republic ranks among the weak-family societies: in 2000-2001 the divorce rate was 57 divorces per 100 marriages; in the same period $22.6 \%$ of total live births occurred 
outside marriage; according to the 2001 census, $29.9 \%$ of all private households were single-person households. In the same census $62.2 \%$ of men and $56.0 \%$ of women admitted to having no religious affiliation. All the above indicators, which are usually assumed to be connected with high suicide rates, have been rising during the past two or three decades in the Czech Republic. Suicide rates have nonetheless been declining. It is just possible that the classic predictors of suicide incidence are no longer compelling.

To examine Durkheim's thesis that changes in suicide rates may be attributed to specific changes in the social environment, Makinen [1997] analysed trends in suicide rates in several European countries in the early 1960s and late 1970s. He found an association between high suicide rates and the process of the erosion of the traditional family, which was indicated by a higher frequency of divorce, a higher proportion of females in paid employment, and fewer children. However, the changes in suicide rates were unrelated to either the levels of or the changes in these social variables. European countries with 'modern' family characteristics experienced a 'suicide boom' during the 1960s, but as the boom subsided the association between suicide rates and social characteristics vanished. Makinen [1997] questioned the relationship between Durkheim's suicidogenic social indicators and suicide rates, hypothesising that a society reacts to social change in general, and to the transformation of family from 'traditional' to 'modern' in particular, by an increase in the incidence of suicide. However, in the course of time, as society becomes accustomed and adapts to the social patterns associated with 'modernity', the indicators lose their predictive capacity with respect to the incidence of suicide. The continuing decline of suicide rates in the Czech Republic, despite the recent economic and social change, may be indicative of such a case.

Thomas G. Masaryk's theory of the relationship between suicide rates and the religious climate of a society is another example of an association that has been extensively discussed for more than a century [Clarke 2003]. In a monograph published in 1881 Masaryk demonstrated how the mass phenomenon of suicide developed as a result of modern cultural life in general and owing to the decline in religiosity among the masses in particular. Drawing on historical examples, he observed that suicide rates increased during periods of social unrest, a weakening of order, and the waning of religious faith. He also noticed an association between suicide rates and education levels, in which he saw an explanation for contemporary prevalent differences in the incidence of suicide. Masaryk also pointed out the differences in suicide rates among the Germanic, Romanesque and Slavic nations, which he attributed to an unbalanced education, lacking moral and religious content. Although the transformation of traditional societies is now studied in the context of changes among a wider range of factors, in the 20th century Masaryk's 'religiosity of the masses' continues to be one of them. In a recent study Neeleman and Lewis [1999] looked at twenty-six countries and investigated the relationship between suicide rates and an aggregate index of religiosity, controlling for socio-economic conditions. Adjusted for socio-economic variation, the negative associations 
of male suicide rates with religiosity only were apparent in the thirteen least religious countries. The authors concluded that men are less likely to commit suicide in a religious society regardless of their attitudes toward religion. Clarke, Bannon and Denihan [2003] attempted to verify Masaryk's theory using data for Ireland. They concluded that both social supports and intolerance of suicide constitute the protective effect of a community's religious climate, diminishing the inclination to suicidal behaviour. Although religiosity may be a marker for other, not clearly recognised factors, it is an indicator whose validity emerged even in the analysis of regional variation in suicide rates in the Czech Republic.

\section{Social correlates of suicide}

Each act of self-destruction results from an individual's decision, which reflects, inter alia, that person's psychological and social characteristics and circumstances. The external influencing factors - in Durkheim's parlance, the suicidogenic factors - identify the existence and the distribution of the parameters within which individuals make their choices. Social, cultural and economic factors, irrespective of how closely they may be correlated with the incidence of suicidal acts, do not determine an individual's propensity to suicide. 'External factors...cause no particular individual to commit suicide but act to generate an overall effect' [Cresswell 1974: 158]. However, cultural and social characteristics potentially affect the variation in the incidence of suicide in another way: through differential reporting or misreporting of the event as suicide. In Farberow's [1975: xiii] words: '...culture will define and direct the way in which suicide occurs, is reacted to, and is reported'.

Unfortunately, the cause-of-death statistics only provide very limited social, cultural and economic information about the deceased persons. One way to get around this problem is to attempt an indirect approach, by analysing regional differences in the incidence of suicide in relation to the variation in the social and economic characteristics of the regional populations. However, this approach leads to ecological correlations, and, as Robinson [1950] so well pointed out, the limitations of ecological correlations in causal analysis must be borne in mind.

A preliminary analysis of suicide statistics by district indicated that the ratio of 'uncertain' to 'certain' suicides varied regionally. To reduce the possibility that such variation could affect the results of the regional analysis, we calculated the district suicide rates using the total number of 'certain' and 'uncertain' suicides. The resulting average annual suicide rates for 1996-2000 were 36.1 and 9.1 per 100000 men and women, respectively.

The Czech Republic is divided into seventy-six administrative districts. For the regression analysis the directly standardised regional suicide rates were calculated for the population aged 15-84 years, males and females taken together. The standard used was the age structure of the population as of 1 July 1998. The selected independent variables to be correlated with the incidence of suicide during the 
Table 5. Correlation coefficients of selected regional characteristics and incidence of suicide. Czech Republic, 1996-2000

\begin{tabular}{lcc}
\hline Characteristics & $\mathrm{R}$ & Significance \\
\hline National heterogeneity & 0.518 & 0.000 \\
Locally born & -0.590 & 0.000 \\
Gypsies & 0.474 & 0.000 \\
Religiosity & 0.583 & 0.000 \\
Low level of education & 0.410 & 0.000 \\
Unemployment & 0.226 & 0.048 \\
Induced abortion & 0.581 & 0.000 \\
Criminality & 0.244 & 0.032 \\
\hline
\end{tabular}

Note: For more about characteristics, see Annex A.

1996-2000 period are listed in Annex A, along with their interpretation and the anticipated association. However, it must be kept in mind that the selected variables are merely surrogates of what are likely to be the real causal factors behind suicidal acts.

Bivariate correlation between standardised district suicide rates and each of the selected independent variables suggests a close association (at $\alpha \leq 0.05$ ) with abortion ratios, religiosity, and low homogeneity of the population (in terms of the index of heterogeneity as well as the percentage of locally born). Weaker associations, though still statistically significant, were found with variables describing levels of criminality and unemployment (Table 5). However, some of the independent variables are highly inter-correlated, and their explanatory value is thus reduced. This is particularly the case of the index of heterogeneity, the proportion of the locally born population, the index of religiosity, and the incidence of abortion.

Therefore, we carried out a stepwise regression analysis: by means of a stepby-step addition of the independent variables the combination of three variables 'explained' $50 \%$ of the regional variation in suicide rates. The explanatory variables were the abortion ratio, the locally born population, and the limited level of education, in that order. None of the other independent variables made a further significant contribution to the explained variance (Table 6). The resulting equation estimating regional suicide rate is

$$
\hat{Y}=18.623-0.186 X_{1}+0.163 X_{2}+1.125 X_{3},
$$

where

$\hat{Y}$ is the directly standardised district suicide rate (based on recorded suicides plus open verdicts) per 100000 persons aged 15-84 years;

$\mathrm{X}_{1}$ is the proportion of locally born persons in the district population;

$\mathrm{X}_{2}$ is the ratio of induced abortions per 100 live births in the district; and

$\mathrm{X}_{3}$ is the proportion of persons aged $15+$ years with less than elementary education. 
Table 6. Multiple Stepwise regression of regional standardised suicide rates $\left({ }^{*}\right)$ and significant explanatory variables; Czech Republic, 1996-2000

\begin{tabular}{|c|c|c|c|c|}
\hline Variables & $\mathrm{R}$ & $\mathrm{R}^{2}$ & Beta & Significance \\
\hline \multicolumn{5}{|l|}{ Dependent variable: } \\
\hline Suicide rate $^{*}$ per 100000 & 0.709 & 0.502 & & \\
\hline \multicolumn{5}{|l|}{ Independent variables: } \\
\hline \multicolumn{3}{|l|}{ Abortion ratio } & 0.375 & 0.000 \\
\hline \multicolumn{3}{|c|}{ Proportion of locally born population } & -0.330 & 0.000 \\
\hline \multicolumn{3}{|c|}{ Proportion of people with a low level of education } & 0.217 & 0.018 \\
\hline
\end{tabular}

Note: ${ }^{*}$ Deaths recorded as suicides, males + females, age group 15-84 years; standard=age distribution of the population of Czech Republic on 1 July 1998.

Table 7. Age standardised mortality ratios: total mortality and suicides in the age group 40-84 years by level of education and gender, Czech Republic, 1999-2000

\begin{tabular}{lcccc}
\hline Level of education & \multicolumn{2}{c}{ All deaths } & \multicolumn{2}{c}{ Suicides } \\
& Males & Females & Males & Females \\
\hline Elementary & 1.338 & 1.010 & 1.464 & 0.817 \\
High school (without certificate) & 1.049 & 1.093 & 1.033 & 1.028 \\
High school (with certificate) & 0.796 & 0.949 & 0.700 & 1.302 \\
Tertiary education & 0.578 & 0.646 & 0.627 & 0.873 \\
Total & 1.000 & 1.000 & 1.000 & 1.000 \\
\hline
\end{tabular}

Source: Rychtaříková [2002].

The districts with comparatively highly standardised suicide rates were those in which there was a high incidence of induced abortion and a strong prevalence of low education, and in which the population was rather heterogeneous, that is, where a large proportion of the population had moved in from other parts of the country or from abroad.

The positive association of the risk of suicide with the level of education may have a direct component apart from the hypothesised effect. A study by Rychtařiková [2002] found that men aged 40-84 with a low level of education had the highest propensity to suicide (1.464, i.e. $46 \%$ higher than the national average), while those with tertiary education had the lowest $(0.627$, i.e. $37 \%$ below the national average). This pattern was very similar to that of differential death rates from all causes (Table 7). Women's suicide rates by educational level did not show a consistent pattern. 
Table 8. Suicide rates and unemployment, Czech Republic, annual average 1996-2000 (per 100000 inhabitants)

\begin{tabular}{lcccc}
\hline Employment status & \multicolumn{4}{c}{ Age group } \\
& $15-34$ & $35-59$ & $15-59$ & $0-85^{+}$ \\
\hline Total population & 3.5 & 7.3 & 10.8 & 12.4 \\
Seeking employment & 14.7 & 26.1 & 40.8 & 41.3 \\
\hline
\end{tabular}

Source: Data from Institute of Health Information and Statistics of the Czech Republic

In general, Masaryk's theory of the 'physical and mental organisation of man' as the underlying factor of suicidal behaviour appears to be reflected in our model, in which 'social disorganisation' variables are of importance. In the highly industrialised regions of the country, which attract employment-seeking migrants from other parts of the country (as well as from abroad), the standardised suicide rates are generally above the national average. Migration is a selection process and is heavily weighted by single persons whose suicide risk is typically higher than average. The process itself leads to the interruption of cultural traditions and family links and supports, resulting in potential social isolation and loneliness and particularly in aggravating any crisis situations. Such crises include prolonged unemployment, which appears especially to increase the risk of self-inflicted harm: in the Czech Republic suicide rates were four times higher among unemployed persons of working age (15-59 years) than in the total population of that age group (Table 8). Among unemployed persons who committed suicide, an aggravating factor was the comparatively high rate of alcohol and drug abuse: alcohol abuse was reported in $46 \%$ and drug abuse in $24 \%$ of all cases of suicide among the unemployed, in contrast to $24 \%$ and $11 \%$, respectively, among all suicides [Dzúrová and Dragomirecká 2002: 68].

\section{Conclusions}

In many respects the ecological characteristics of suicides in the Czech Republic are not any different from those found in other countries. This is particularly true of the patterns in the differences in the incidence of suicide between men and women, by age, and by marital status. The decline in suicide rates among older men and women may be attributed to improved palliative care and pain management in the case of chronic illness, and to the widening of access to institutional social and health care for the elderly. In addition, since the end of the communist regime, non-governmental organisations have emerged that provide support and counselling in these areas. Freedom to express one's religious affiliation may also play a role. However, what is disconcerting is the stagnation and, more recently, a possible increase in suicide rates among teenagers and young adults. This tendency gives rise to several social concerns, especially because of its association with the problems school-leavers 
face in obtaining employment and with rising levels of alcohol and drug abuse among young people. The new competitive environment and an increasing emphasis on a person's individual responsibility may also exert a strong influence.

The observed regional differences in the incidence of suicide appear to be related to the structure of the regional populations rather than to the economic characteristics of the regions. A higher than average incidence of suicide was observed in the regions with a large proportion of immigrants. In the new environment migrants may suffer from feelings of isolation, from the interruption of social and familial links, and from a loss of identity. In contrast, low suicide rates were recorded in the regions that have traditionally been dominated by a Roman Catholic population.

It is worth mentioning that the trend in suicide rates in the Czech Republic since the 1970s appears to support Makinen's hypothesis. Traditional social indicators relating to suicide incidence, such as divorce or extra-marital pregnancy, appear to be losing their predictive power as society is changing. Events that may previously have been considered as casting social shame on the individual and his or her family may have lost much of their stigmatising effect.

Notwithstanding the ecological correlates of the incidence of suicide, the decision to take one's life is an individual decision, perceived as the only solution to pressing problems. However, the identification of areas with a comparatively high incidence of suicidal behaviour may assist in designing policies and measures to alleviate this problem. Such policy measures may range from broader-based economic assistance, such as developing job opportunities, especially for young people, to specific mental health-related assistance, such as socio-psychiatric counselling services.

DAGMAR DzÚROVÁ is an assistant professor of geo-demography at the Faculty of Science, Charles University in Prague. Her research interests include: demographic analysis of public health and quality of life in the Czech Republic and developed countries, geographic analysis of environmental and psychopathological effects on human health, and epidemiological analyses of mental health.

LADO RUzicKA is a fellow at the Academy of the Social Sciences in Australia. He was formerly associate professor of health and biostatistics at the Medical School of Hygiene, Charles University in Prague, and later served as a consultant at the United Nations Secretariat, Department of Economic and Social Affairs Population Division, in New York, and a reader in Population Studies at the International Institute of Population Sciences in Mumbai. He is a retired professor of demography at the Australian National University in Canberra. His main areas of interest and research are: population health, epidemiologic and mortality transition with special reference to Asian countries, and suicide.

EVA DRAGOMIRECKÁ works as a researcher in the Department of Social Psychiatry at the Prague Psychiatric Centre. Her particular area of interest is social epidemiology of mental health and assessment methods, especially the quality of life. 


\section{References}

Clarke, Ciaran, S., F.J. Bannon, and A. Denihan. 2003. 'Suicide and Religiosity - Masaryk's Theory Revisited.' Social Psychiatry and Psychiatric Epidemiology 38 (9): 502-506.

Cresswell, Peter. 1974. 'Suicide: The Stable Rates Argument.' Journal of Biosocial Science 6: 151-161.

Durkheim, Emile. 1952. Suicide. London: Routledge and Kegan Paul.

Dzúrová, Dagmar and Eva Dragomirecká (eds.) 2002. Sebevražednost obyvatel České republiky $v$ obdobi transformace společnosti (Suicide among the Population of the Czech Republic during the Process of the Transformation of Society). Charles University in Prague, Department of Social Geography and Regional Development.

Farberow, Norman, L. 1975. 'Introduction.' Pp. i-xvii in Suicide in Different Cultures, edited by Norman, L. Farberow. University Park Press, Baltimore University Park Press.

Gove, Walter, R. 1973. 'Sex, Marital Status, and Mortality.' American Journal of Sociology 79: 45-67.

Makinen, Ilkka, H. 1997. 'Are There Social Correlates of Suicide?' Social Science and Medicine 44 (12): 1919-1929.

Masaryk, Tomáš, G. 1881. Der Selbstmord als soziale Massenerscheinung der modernen Zivilisation. Vienna: C. Konegen. (Engl.trans. Suicide and the Meaning of Civilization. The Heritage of Sociology. Chicago: University of Chicago Press 1970.)

Neeleman J. and G. Lewis. 1999. 'Suicide, Religion, and Socioeconomic Conditions. An Ecological Study in 26 Countries, 1990.' Journal of Epidemiology and Community Health 53: 204-210.

O'Carroll, Patrick. 1989. 'A Consideration of the Validity and Reliability of Suicide Mortality Data.' Suicide and Life-Threatening Behavior 19: 1-16.

Reher, David, S. 1998. 'Family Ties in Western Europe: Persistent Contrasts.' Population and Development Review 24 (2): 203-234.

Robinson, William S. 1950. 'Ecological Correlation and the Behaviour of Individuals.' American Sociological Review 15: 351-357.

Rychtaříková, Jitka. 2002. 'Sebevražednost podle vzdělání.' (Suicide by Education) Pp. 36-41 in Sebevražednost obyvatel České republiky v období transformace společnosti, edited by D. Dzúrová and E. Dragomirecká. Charles University in Prague, Department of Social Geography and Regional Development.

Ruzicka, Lado and C.Y. Choi. 1999. 'Youth Suicide in Australia.' Journal of the Australian Population Association 16 (1/2): 29-46.

Sebevraždy/Suicides 1990-2002. Institute of Health Information and Statistics of the Czech Republic.

World Health Statistics Annual 1996. World Health Organisation, Geneva. 


\section{Appendix A.}

Selected population characteristics of the regions and their assumed association with the variation in the incidence of suicide

Characteristics:

Proportion of persons of a nationality other than Czech, Moravian or Silesian

Proportion of persons born within the given region

Proportion of ethnic Gypsies in the district's population

Proportion of persons declaring no religious affiliation

Proportion of persons aged 15+ with less than basic/elementary education

Percentage of unemployed in the regional labour force

Number of induced abortions per 100 live births

Incidence of criminal acts in the region (per 1000 population)

\section{Hypothesis:}

Greater heterogeneity of the population is assumed to be associated with lesser social cohesion and a higher incidence of suicide

\section{A higher proportion of Gypsies may result in more frequent inter-personal conflicts and a higher incidence of suicide}

Religiosity is assumed to provide some protection against self-inflicted harm; a higher incidence of suicide is expected in the regions with a low proportion of persons declaring religious affiliation

A low level of education is deemed to reduce employment opportunities and choice of jobs, limit the quality of life, and increase the risk of psychopathological disturbances, including suicide

A high level of unemployment may result in a higher incidence of suicide

A high abortion ratio may indicate a higher incidence of weak family structures and thus a higher propensity to suicide

A higher level of criminality may indicate social disorganisation and a higher propensity to suicide 
